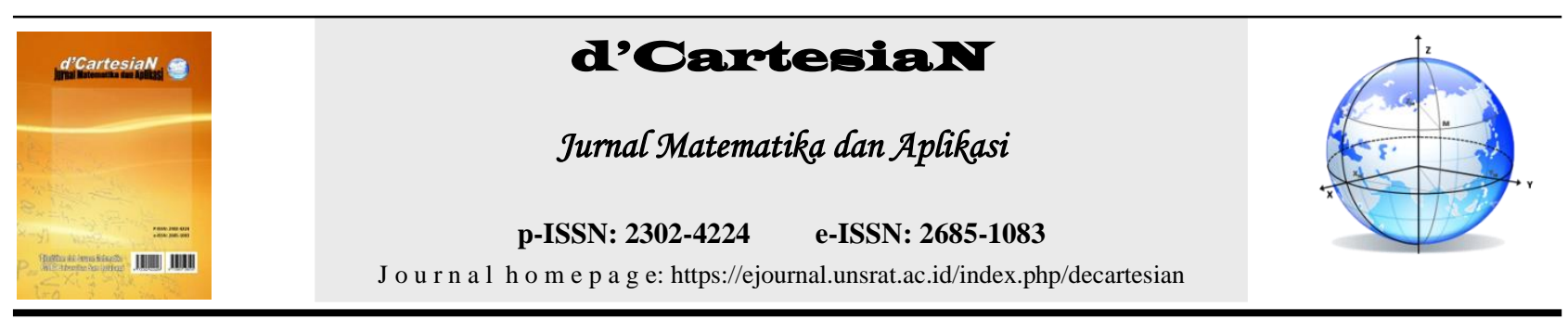

\title{
Metode Quasi Monte Carlo Dengan Barisan Bilangan Acak Halton Dalam Menentukan Nilai Kontrak Opsi Tipe Binary Pada Saham PT. Gudang Garam, Tbk.
}

\author{
Josia A. P. Sumampouw ${ }^{1}$, Chriestie E. J. C. Montolalu ${ }^{1}$, Tohap Manurung1 ${ }^{*}$ \\ ${ }^{1}$ Jurusan Matematika-Fakultas Matematika dan Ilmu Pengetahuan Alam-Universitas Sam Ratulangi Manado, Indonesia
}

*Corressponding author : tohapm@unsrat.ac.id

\begin{abstract}
A B S T R A K
Investasi merupakan perjanjian atas sejumlah dana atau aset lainnya yang dilakukan dimasa sekarang dengan tujuan agar mendapatkan keuntungan dimasa yang akan datang. Salah satu alternatif dalam berinvestasi adalah opsi. Kontrak opsi saham merupakan bagian terpenting dalam strategi berinvestasi. Ada banyak metode yang dapat digunakan untuk menentukan nilai kontrak opsi saham, salah satunya adalah metode Quasi Monte Carlo dengan barisan bilangan acak Halton. Tujuan dari penelitan ini adalah untuk menentukan nilai kontrak opsi saham tipe binary menggunakan metode Quasi Monte Carlo dengan barisan bilangan acak Halton pada saham PT Gudang Garam, Tbk. Dengan menggunakan metode ini, hasil penelitian sebanyak 300.000 simulasi diperoleh nilai kontrak opsi call pada angka 4.494,834 dengan standard error sebesar 9,985 pada simulasi ke 282.00o, dan nilai kontrak opsi put pada angka 4.952,812 dengan standard error sebesar 9,982 pada simulasi ke 178.000 .
\end{abstract}

\section{INFO ARTIKEL}

Diterima : 12 Juli 2020

Diterima setelah revisi : 29 Agustus 2020

Tersedia online : 5 Januari 2021

\author{
Kata Kunci: \\ Opsi Binary \\ Monte Carlo \\ Quasi Monte Carlo \\ Bilangan Acak Halton
}

\begin{abstract}
A B S T R A C T
Investment is a contract of a number of fund or another assets, which is done in the present with the aim of getting profit in the future. One of the investment alternative is option. Contract option are the most important part of an investment strategy. There are many methods used in determining the option contract value, one of this is the Monte Carlo Quasi method with the Halton random. The purpose of this study is to determine the value of binary type option contract using the Quasi Monte Carlo method with the Halton random number on PT Gudang Garam, Tbk. By using this method, the results of this study with simulation 282.000 generate standard error is 9,985 and the call option at 4.500,778. Likewise, with simulation 178.000 generate standard error is 9,982 and the put option at $4.592,812$
\end{abstract}

\section{ARTICLE INFO:}

Accepted : 12 July 2020

Accepted after revision : 29 August 2020

Available online : 5 January 2021

\author{
Keywords: \\ Binary Option \\ Monte Carlo \\ Quasi Monte Carlo \\ Halton Random Number
}

\section{PENDAHULUAN}

Salah satu alternatif investasi yang dapat dipilih oleh investor adalah produk derivatif. Produk derivatif merupakan suatu instrumen keuangan yang nilainya bergantung pada suatu aset yang mendasarinya. Salah satu jenis produk derivatif adalah opsi. Aset yang mendasari opsi dapat berupa saham, emas, mata uang asing, dan lain-lain [1]. Opsi merupakan suatu jenis kontrak yang memberikan hak kepada investor untuk membeli atau menjual suatu aset pada harga dan waktu yang telah disepakati bersama [2]. Opsi telah lama dikenal, tetapi secara resmi diperdagangkan di pasar modal pada Oktober 1973 di Chicago Board of Option Exchange (CBOE). Di Indonesia, produk ini dikenal dengan nama KOS (Kontrak Opsi Saham) yang pertama kali diperdagangkan di Bursa Efek Indonesia (BEI) di tahun 2004.

KOS adalah efek yang memuat opsi beli (call option) atau opsi jual (put option) atas saham perusaan tercatat yang menjadi saham dasar dalam perdagangan seri Kontrak Opsi Saham dengan jumlah dan harga yang ditetapkan oleh bursa untuk setiap seri Kontrak Opsi Saham sebagai acuan dalam eksekusi [3]. Pemegang opsi tipe Amerika dapat mengeksekusi setiap haknya setiap saat hingga waktu jatuh tempo, sedangkan opsi tipe Eropa hanya memberikan kesempatan kepada pemegang opsi untuk mengeksekusi haknya pada saat jatuh tempo, sementara opsi Binary memungkinkan pemegang opsi untuk memprediksi arah pergerakan saham, dimana apabila pemegang opsi berhasil dengan prediksinya maka pemegang opsi tersebut akan memiliki hasil tetap. Namun apabila aset memberikan hasil yang berbeda dari yang telah diprediksi, maka pemegang opsi akan mengalami kerugian.

Penentuan nilai kontrak opsi merupakan bagian terpenting dalam menentukan strategi berinvestasi. Kontrak opsi dapat digunakan untuk meminimalkan risiko sekaligus memaksimalkan keuntungan dengan daya ungkit atau leverage yang besar [4].

Menentukan harga opsi dengan jangka waktu tertentu tidaklah mudah. Namun saat ini, ada banyak metode-metode yang terus berkembang dalam rangka 
membantu investor dalam menentukan keputusan untuk berinvestasi. Model dan metode yang dapat digunakan untuk menentukan harga opsi yaitu Binomial Option Pricing Model (BOPM), model Black Scholes, simulasi Monte Carlo, Metode Quasi Monte Carlo, dan lain sebagainya. Metode Quasi Monte Carlo merupakan metode Monte Carlo yang bilangan acaknya merupakan bilangan acak low discrepancy (barisan pembeda lemah). Salah satu bilangan acak low discrepancy yaitu bilangan acak Halton. Ratnasari et al., (2017) telah melakukan perbandingan antara penggunaan Metode Monte Carlo dan Metode Quasi Monte Carlo dalam menentukan harga opsi. Dari hasil penelitiannya, Metode Quasi Monte Carlo menunjukkan hasil dengan error lebih kecil. Sehingga, metode Quasi Monte Carlo dapat dianggap metode yang efektif untuk menentukan harga opsi. Untuk itu dalam penelitian ini akan menggunakan metode Quasi Monte Carlo dengan barisan bilangan acak Halton dalam menentukan nilai kontrak opsi PT Gudang Garam, Tbk.

\section{Komponen Opsi}

Komponen-Komponen opsi terdiri dari:

1. Kontrak resmi merupakan sebuah kontrak dimana terdapat dua pihak yang sepakat membuat suatu kontrak yang mempunyai sifat mengikat yang tidak dapat dibatalkan secara sepihak.

2. Hak opsi (bukan suatu kewajiban) yang merupakan hak untuk membeli yang disebut opsi call dan hak untuk menjual yang disebut opsi put.

3. Aset Dasar atau underlying asset adalah aset yang mendasari derivatif yang diperjualbelikan. Aset ini dapat berbentuk berbagai macam, bisa berupa saham, EFT, index, futures, currencies, bonds, commodity dan lain-lain. Dalam penelitian ini akan dibahas opsi dengan aset dasar (underlying assets) berupa saham.

4. Harga Perjanjian atau Strike Price adalah harga dimana aset yang dimaksudkan dalam kontrak resmi tersebut diperjualbelikan.

5. Waktu Jatuh Tempo atau Expiration Date adalah hari terakhir dimana sebuah opsi dapat dieksekusi. Setiap opsi mempunyai jangka waktu hidup atau masa berlaku mulai dari 1 hari sampai dengan maksimum 3 tahun, bergantung pada broker yang digunakan.

Berdasarkan jenis kontrak, opsi terbagi dua: Opsi call yaitu memberikan hak kepada holder untuk membeli suatu aset saham tertentu dengan jumlah tertentu dan pada harga yang telah ditentukan selama periode waktu tertentu, dan Opsi Put yaitu memberikan hak kepada holder untuk menjual suatu aset saham tertentu dengan jumlah tertentu dan pada harga yang telah ditentukan selama periode waktu tertentu.

\section{Faktor-Faktor Yang Harus Diperhatikan Dalam Bertransaksi Opsi}

Dalam bertransaksi opsi beli dan jual, terdapat hal-hal yang perlu diperhatikan dalam kontrak opsi adalah:

1. Perusahaan yang sahamnya akan dibeli atau dijual.

2. Jumlah saham yang dapat dibeli atau dijual.

3. Harga pembelian (penjualan) atau harga penyerahan saham tersebut.

4. Tanggal berakhirnya hak membeli (menjual).

\section{Opsi Tipe Binary}

Salah satu jenis ospi eksotik yaitu opsi binary. Terdapat dua tipe opsi binary yaitu tipe cash-or-nothing dan asset-or-nothing. Asset-or-nothing merupakan opsi binary dimana pada jenis transaksi ini jumlah profit bersifat fleksibel, bergantung pada posisi harga saham pada saat jatuh tempo [5]. Untuk penentuan pay-off opsi call dapat dirumuskan:

$$
P_{c}=\left\{\begin{array}{rr}
c_{a n}, & S_{t}>K \\
0, & S_{t} \leq K
\end{array}\right.
$$

$K$ merupakan harga kesepakatan atau strike price, $S_{t}$ merupakan harga saham pada saat jatuh tempo, dan $c_{a n}$ dapat ditentukan dengan persamaan berikut:

$$
c_{a n}=e^{-r T}\left(S_{t}-K\right)
$$

Dengan $r$ merupakan suku bunga dan $T$ merupakan periode saham.

Begitu juga dengan opsi put, untuk penentuan pay-off dapat dirumuskan:

$$
P_{p}=\left\{\begin{aligned}
p_{a n}, & S_{t}<K \\
0, & S_{t} \geq K
\end{aligned}\right.
$$

Untuk $p_{a n}$ dapat ditentukan dengan persamaan berikut:

$$
p_{a n}=e^{-r T}\left(K-S_{t}\right)
$$

\section{Volatilitas}

Volatilitas adalah ukuran dari perubahan harga aset tanpa memperhatikan arahnnya. Estimasi volatilitas dihitung dengan rumus sebagai berikut:

$$
\sigma=\sqrt{\frac{\frac{1}{n-1} \sum_{t=1}^{n}\left(r_{t}-\mu\right)^{2}}{\tau}}
$$

Dengan galat standar (standard error) yaitu:

$$
S E=\frac{\sigma}{\sqrt{2 n}}
$$

Dimana $\tau$ adalah panjang interval waktu dalam satuan tahun, $\mu$ adalah nilai rata-rata dari continuously compounded return. Rumus continuously compounded return diberikan:

$$
r_{t}=\ln \left(\frac{S_{t}}{S_{t-1}}\right)
$$

\section{Quasi Monte Carlo}

Simulasi Monte Carlo adalah suatu metode yang menghendaki model simulasi yang mengikutsertakan bilangan acak dan sampel yang berbasis pada komputer. Simulasi Monte Carlo dikenal dengan istilah sampling simulation atau Monte Carlo Sampling Technique. Simulasi ini menggunakan data sampling yang telah ada (historical data) dan telah diketahui distribusi datanya. Penggunaan metode Monte Carlo memerlukan sejumlah besar bilangan acak, dan hal tersebut semakin mudah dengan perkembangan pembangkit bilangan-bilangan acak, yang jauh lebih cepat dan praktis dibandingkan dengan metode sebelumnya yang menggunakan tabel bilangan acak untuk sampling statistik [6]. Metode Monte Carlo menggunakan bilangan acak berdistribusi normal baku yaitu: 


$$
S(t+\Delta t)=S(t) \exp \left[\left(\mu-\frac{\sigma^{2}}{2}\right) \Delta t+\sigma \epsilon \sqrt{\Delta t}\right]
$$

dengan $S(t)$ merupakan harga saham pada waktu $t$ dan $\epsilon$ adalah bilangan acak berdistribusi normal $(\epsilon \sim N(0,1))$ [5].

Metode Quasi Monte Carlo merupakan metode Monte Carlo yang menggunakan barisan quasi acak sebagai pengganti dari bilangan acak. Barisan quasi acak ini pada umumnya memperbaiki kinerja dari simulasi Monte Carlo sehingga memberikan hasil yang lebih akurat. Terdapat beberapa barisan quasi acak, antara lain Van der Cormput, Halton, Faure, dan Sobol.

Barisan Halton merupakan barisan pembeda lemah (low discrepancy) yang paling sederhana dengan banyak dimensi. Barisan low discrepancy juga dikenal sebagai barisan quasi acak, yang mana bilanganbilangannya terdistribusi acak lebih baik dalam suatu interval dari pada bilangan Pseudo Random yang digunakan simulasi Monte Carlo. Untuk dapat memperoleh barisan bilangan Halton, perlu untuk mengetahui barisan quasi acak Van der Corput. Barisan quasi acak Van der Corput adalah barisan low discrepancy satu dimensi yang paling sederhana dengan basis bilangan prima.

\section{METODE PENELITIAN}

\section{Waktu dan Tempat Penelitian}

Penelitian ini dilaksanakan mulai bulan Oktober 2019 sampai Januari 2020, mulai dari penyusunan proposal, pengambilan dan pengolahan data, dan penarikan kesimpulan. Pengolahan data dilakukan di Laboratorium Komputasi Jurusan Matematika, Fakultas Matematika dan Ilmu Pengetahuan Alam, Universitas Sam Ratulangi Manado.

\section{Analisis Data}

Data yang digunakan dalam penelitian ini adalah data sekunder berupa harga penutupan (close price) dari saham PT Gudang Garam, Tbk, serta tingkat bunga bebas risiko yang ditetapkan oleh Bank Indonesia. Adapun data sekunder diperoleh dari website http://finance.yahoo.com. Pengolahan data dilakukan dengan menggunakan software Microsoft Office Excel dan Matlab. Sumber yang digunakan dari buku, jurnal ilmiah, dan internet.

Langkah-langkah yang digunakan pada penelitian ini yaitu:

1. Mengambil data historis closing price saham PT Gudang Garam, Tbk. periode 30 Oktober 2014 sampai 30 Oktober 2019.

2. Menghitung tingkat pengembalian (return) dari closing price saham PT Gudang Garam Tbk, dengan menggunakan persamaan (4).

3. Menetapkan parameter yang diperlukan untuk mensimulasikan nilai closing price saham PT Gudang Garam Tbk, yaitu S(o) (nilai awal), $\mu$ (ratarata), $\mathrm{T}$ (waktu jatuh tempo), $\mathrm{K}$ (harga kesepakatan), $r$ (tingkat suku bunga), dan $\sigma$ (standar deviasi) yang diperoleh dari data historis. Nilai T dan K sudah ditetapkan sebelumnya.
4. Melakukan simulasi harga saham menggunakan persamaan (5). Substitusikan parameter S(o) (nilai awal), $\mu$ (rata-rata), $\mathrm{T}$ (waktu jatuh tempo), K (harga kesepakatan), $r$ (tingkat suku bunga), dan $\sigma$ (standar deviasi) pada persamaan (3). Membangkitkan barisan bilangan acak. Variabel acak $\epsilon$ merupakan bilangan acak Halton.

5. Menentukan nilai pay-off opsi put dan opsi call menggunakan asset-or-nothing pada persamaan (1) dan (2).

6. Menaksir nilai opsi put dan opsi call yang diperoleh dari metode quasi Monte Carlo dengan merataratakan nilai payoff dari opsi tersebut. Akan dilihat nilai dari hasil simulasi.

7. Menentukan kesimpulan.

\section{HASIL DAN PEMBAHASAN}

\section{Deskripsi Data}

Dalam penelitian tugas akhir ini digunakan data harga penutupan saham (closed price) harian pada periode 30 Oktober 2014 - 30 Oktober 2019 yang diambil dari website Yahoo Finance (http://finance.yahoo.com). Data ini digunakan untuk estimasi volatilitas.

Nilai pay-off opsi yang akan dihitung adalah nilai pay-off opsi beli dan nilai pay-off opsi jual yang dimulai pada 30 Oktober 2019 dengan waktu jatuh tempo 31 Januari 2020. Oleh karena itu, harga saham yang dijadikan sebagai harga saham awal dan sebagai harga kesepakatan untuk menghitung nilai pay-off opsi adalah harga penutupan saham PT. Gudang Garam Tbk pada 30 Oktober 2019.

Suku bunga bebas risiko yang digunakan dalam penelitian ini adalah suku bunga acuan yang diterbitkan oleh Bank Indonesia yaitu sebesar 5\%. Data ini diperoleh dari website resmi Bank Indonesia (www.bi.go.id).

\section{Menghitung Nilai Log Return}

Nilai Log Return dari saham PT Gudang Garam, Tbk dihitung dari harga penutupan saham harian. Untuk $t=1$,

$$
r_{1}=\ln \left(\frac{57750}{56350}\right)=0.02454
$$

Perhitungan diulang untuk periode 30 Oktober 2014 sampai 30 Oktober 2019.

\section{Estimasi Volatilitas Data Historis Harga Saham} berikut:

Untuk volatilitas harga saham diperoleh sebagai

$$
\begin{aligned}
\sigma & =\sqrt{\frac{\frac{1}{n-1} \sum_{t=1}^{n}\left(r_{t}-\mu\right)^{2}}{\tau}} \\
& =\sqrt{\frac{\frac{1}{1258-1} \sum_{t=1}^{n}\left(r_{t}-0.00000425\right)^{2}}{1 / 261}} \\
& =0.3363
\end{aligned}
$$




\section{Simulasi Harga Penutupan Saham Harian}

Untuk simulasi harga penutupan saham harian, diperlukan barisan bilangan acak Quasi yang berdistribusi seragam yang kemudian ditransformasikan ke bilangan yang berdistribusi normal. Simulasi harga penutupan saham (closing price) dilakukan untuk memperoleh harga penutupan saham pada saat jatuh tempo. Setelah dilakukan simulasi kemudian akan ditentukan pay-off dari harga saham yang didapat. Hasil simulasi yang diperoleh untuk opsi call sebagai berikut:

Tabel 1. Hasil Simulasi Untuk Opsi Call

\begin{tabular}{|l||l|l||}
\hline \multicolumn{1}{|c|}{$\boldsymbol{n}$} & Nilai Opsi & Standard Error \\
\hline 100 & 3608.082 & 448.412 \\
\hline 10000 & 4369.853 & 51.855 \\
\hline 100000 & 4380.802 & 16.474 \\
\hline 200000 & 4482.837 & 12.443 \\
\hline 250000 & 4482.494 & 10.587 \\
\hline 282000 & 4494.834 & 9.985 \\
\hline 300000 & 4500.778 & 9.687 \\
\hline
\end{tabular}

Dari tabel 1 diatas tampak perubahan yang diperoleh yaitu dimana semakin banyak jumlah simulasi yang dilakukan, maka standard error-nya akan semakin kecil. Hal ini menunjukan bahwa nilai yang diperoleh telah menuju ke suatu nilai, sehingga semakin banyak simulasi yang dilakukan maka penyimpangannya akan semakin kecil. Dalam simulasi yang ke-282000, standard error yang diperoleh sudah sampai pada 1 digit, sehingga dapat disimpulkan bahwa nilai opsi call adalah sebesar 4494.834 dengan standard error 9.985.

Berdasarkan hukum bilangan besar maka hasil yang diperoleh diatas dapat dikatakan bahwa banyaknya rata-rata sampel sesuai dengan banyaknya simulasi yang dilakukan dan rata-rata yang konvergen pada nilai tengah akan selalu berlaku meskipun banyaknya simulasi ditambah sampai menuju tak hingga. Dengan demikian hukum bilangan besar merupakan suatu penduga dari rata-rata populasi yang memiliki jumlah sangat besar, dalam artian parameter yang dihasilkan merupakan suatu penduga dari rata-rata. Begitu juga dengan opsi put, hukum bilangan besar juga berlaku karena simulasi yang dilakukan pada opsi put juga dilakukan pada opsi call. Sehingga hukum ini berlaku untuk kedua opsi. Dapat dilihat pada tabel 2 sebagai berikut:

Tabel 2. Hasil Simulasi Untuk Opsi Put

\begin{tabular}{|l||l|l||}
\hline \multicolumn{1}{|c|}{$\boldsymbol{n}$} & Nilai Opsi & Standard Error \\
\hline 100 & 4699.625 & 391.020 \\
\hline 10000 & 4720.871 & 42.659 \\
\hline 100000 & 4676.613 & 13.397 \\
\hline 178000 & 4592.812 & 9.982 \\
\hline 200000 & 4609.162 & 9.417 \\
\hline 300000 & 4596.706 & 7.675 \\
\hline
\end{tabular}

Dari tabel 2 tampak perubahan yang diperoleh yaitu dimana semakin banyak jumlah simulasi yang dilakukan, maka standard error-nya akan semakin kecil. Hal ini menunjukan bahwa nilai yang diperoleh telah menuju ke suatu nilai, sehingga semakin banyak simulasi yang dilakukan maka penyimpangannya akan semakin kecil. Dalam simulasi yang ke-1780oo, standard error yang diperoleh sudah sampai pada 1 digit, sehingga dapat disimpulkan bahwa nilai opsi call adalah sebesar 4592.812 dengan standard error 9.982

Berdasarkan hasil dari simulasi opsi call dan opsi put diperoleh bahwa dari sudut pandang pembeli/pemegang opsi dapat dikatakan bahwa pemegang opsi yang akan melakukan transaksi call atau put dengan harga kesepakatan sebesar 56050, memberikan interval profit dan loss yang tertera pada penjelasan sebelumnya, baik opsi call maupun opsi put. Sehingga hasil penelitian ini dapat menjadi acuan interval penentuan nilai kontrak yang diinginkan sesuai dengan kesepakatan antara pemegang opsi (taker) dan penjual opsi (writer).

\section{PENUTUP}

\section{Kesimpulan}

Berdasarkan hasil penelitian yang dilakukan, dapat disimpulkan bahwa penentuan simulasi Quasi Monte Carlo dapat memprediksi harga saham dan menentukan nilai opsi suatu saham. Hasil simulasi nilai opsi yang telah dilakukan menunjukkan bahwa semakin banyak simulasi yang dilakukan maka nilai estimasi rata-rata yang diperoleh semakin konvergen. Dalam penentuan nilai kontrak opsi tipe Binary pada saham PT Gudang Garam, Tbk., dilakukan simulasi sampai 300000 kali dan diperoleh nilai kontrak opsi call pada angka 4.494,834 dengan standard error 9,687 pada simulasi ke 282.ooo. Sedangkan untuk nilai kontrak opsi put berada pada angka 4.952,812 dengan standard error 9,982 pada simulasi ke 178.0oo.

\section{Saran}

Berdasarkan hasil penelitian, hal-hal yang disarankan yaitu :

1. Bagi pemegang opsi untuk aset dasar saham PT Gudang Garam, Tbk dengan periode 31 Oktober 2019 sampai 31 Januari 2020 agar memilih transaksi opsi put.

2. Bagi pemegang opsi dan penjual opsi agar memperhatikan harga kesepakan berdasarkan periode yang disepakati.

\section{REFERENSI}

[1] Tambingon, D.A, Julia T., dan Tohap M. 2019. Black-Scholes Model in Determining European Option Prices on Netflix, Inc. d'Cartesian : Jurnal Matematika dan Aplikasi. 8(2). 80-85.

[2] Joharni. 2017. Penentuan Harga Opsi Tipe Eropa dengan Menggunakan Model Fraksional Black Scholes. Makassar: UIN Alauddin

[3] Seleky, J.S. 2012. Penentuan Nilai Opsi Call Barrier dengan Dividen Tunggal di Bursa Efek Indonesia [thesis]. Bogor: FMIPA IPB.

[4] Bodie, K. dan Marcus. 2006. Investasi. 6th ed. Jakarta: Salemba Empat.

[5] Hull, J.C. 2012. Options, Futures, and Other Derivatifs : Eighth Edition. United States of America: Pearson. 
[6] Kakiay, T. 2004. Pengantar Sistem Simulasi. Yogyakarta: ANDI Yogyakarta.

Josia A. P. Sumampouw (sumampuowjosia@gmail.com)

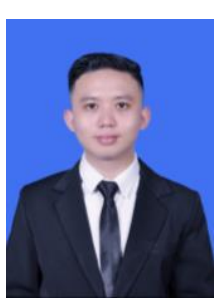

Lahir di Modayag, Sulawesi Utara pada tanggal 17 Mei 1998. Menempuh pendidikan tinggi Jurusan Matematika, FMIPA, Universitas Sam Ratulangi Manado. Tahun 2019 adalah tahun terakhir ia menempuh studi. Makalah ini merupakan hasil penelitian skripsinya yang dipublikasikan.

Chriestie E.J.C. Montolalu (chriestelly@unsrat.ac.id)

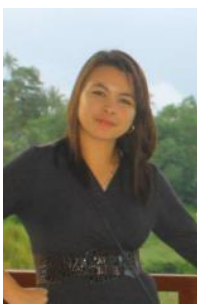

Lahir pada tanggal 10 Desember 1985. Pada tahun 2007 mendapatkan gelar Sarjana Sains (S.Si) yang diperoleh dari Universitas Sam Ratulangi Manado. Gelar Master Of Science (M.Sc) diperoleh dari Universitas Of Queensland Australia pada tahun 2015. Ia bekerja di UNSRAT di Program Studi Matematika sebagai pengajar akademik

tetap UNSRAT.

Tohap Manurung (tohapm@unsrat.ac.id)

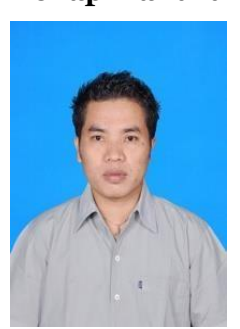

Lahir pada tanggal 24 Desember 1979. Pada tahun 2003 mendapatkan gelar Sarjana Sains (S.Si) yang diperoleh dari Universitas Sumatera Utara. Gelar Magister Sains diperoleh dari Institut Teknologi Bandung padatahun 2010. Ia bekerja di UNSRAT di Program Studi Matematika sebagai pengajar akademik tetap UNSRAT. 